\title{
Pediatric vestibular schwannomas: case series and a systematic review with meta-analysis
}

\author{
Giselle E. K. Malina, BA, ${ }^{1}$ Daniel M. Heiferman, MD, ${ }^{1}$ Loren N. Riedy, BS,1,3 \\ Caroline C. Szujewski, BA, ${ }^{1,3}$ Elhaum G. Rezaii, MPH, ${ }^{1}$ John P. Leonetti, MD, ${ }^{2}$ and \\ Douglas E. Anderson, MD'
}

\begin{abstract}
Departments of ${ }^{1}$ Neurological Surgery and ${ }^{2}$ Otolaryngology, Loyola University Medical Center, Maywood; and ${ }^{3}$ Department of Neurobiology, University of Chicago, Illinois
\end{abstract}

\begin{abstract}
OBJECTIVE Sporadic unilateral vestibular schwannomas are rare in the pediatric population. Little has been reported in the literature on the presentation, tumor size, response to surgical treatment, and recurrence rates in these younger patients. The authors' goal was to describe their institutional experience with pediatric sporadic vestibular schwannomas and to conduct a meta-analysis of the existing literature to provide further insight into the presentation, tumor characteristics, and surgical outcomes for these rare tumors to help direct future treatment strategies.

METHODS The authors performed a retrospective review of all patients 21 years of age or younger with unilateral vestibular schwannomas and without neurofibromatosis type 2 who underwent resection by the senior authors between 1997 and 2019. A systematic review of the literature and meta-analysis was also performed by entering the search terms "pediatric" and "vestibular schwannoma" or "acoustic neuroma," as well as "sporadic" into PubMed. Presentation, treatment, clinical outcomes, and follow-up were analyzed.
\end{abstract}

RESULTS Fifteen patients were identified at the authors' institution, ranging in age from 12 to 21 years (mean 16.5 years). Common presenting symptoms included hearing loss (87\%), headache $(40 \%)$, vertigo (33\%), ataxia $(33 \%)$, and tinnitus (33\%). At the time of surgery, the mean tumor size was $3.4 \mathrm{~cm}$, with four $1-\mathrm{cm}$ tumors. Four patients had residual tumor following their first surgery, $3(75 \%)$ of whom had significant radiographic regrowth that required further treatment. The literature review identified an additional 81 patients from 26 studies with patient-specific clinical data available for analysis. This resulted in a total of 96 reported patients with an overall average age at diagnosis of 12.1 years (range 6-21 years) and an average tumor size of $4.1 \mathrm{~cm}$.

CONCLUSIONS Pediatric vestibular schwannomas present similarly to those in adults, although symptoms of mass effect are more common, as these tumors tend to be larger at diagnosis. Some children are found to have small tumors and can be successfully treated surgically. Residual tumors in pediatric patients were found to have a higher rate of regrowth than those in their adult counterparts.

https://thejns.org/doi/abs/10.3171/2020.3.PEDS19514

KEYWORDS acoustic neuroma; sporadic; vestibular schwannoma; oncology

$\mathrm{V}$ ESTIBULAR schwannomas (VSs), also known as acoustic neuromas, are benign, slow-growing tumors that originate from a vestibular division of the eighth cranial nerve. ${ }^{1}$ They typically originate in the internal acoustic meatus and can grow into the cerebellopontine angle, causing brainstem compression. These tumors most frequently present with hearing loss and tinnitus and primarily occur in adults between the 5th and 6th decades of life with an incidence ranging from 0.6 to 1.9 per 100,000 persons per year. Conversely, these tumors are considerably less common in children. ${ }^{2-4}$ In the pediatric population, these tumors typically present as part of neurofibromatosis type 2 (NF2). In NF2, they characteristically present as bilateral lesions and may be accompanied by other defining lesions such as other schwannomas, meningiomas, and gliomas. ${ }^{5,6}$ Sporadic cases in the pediatric

ABBREVIATIONS GTR = gross-total resection; HB = House-Brackmann; ICP = intracranial pressure; NF2 = neurofibromatosis type 2; NTR = near-total resection; SNHL = sensorineural hearing loss; SRS = stereotactic radiosurgery; STR = subtotal resection; VS = vestibular schwannoma.

SUBMITTED September 6, 2019. ACCEPTED March 30, 2020.

INCLUDE WHEN CITING Published online May 29, 2020; DOI: 10.3171/2020.3.PEDS19514. 
population, without any NF2 characteristics or family history, are extremely rare. ${ }^{2,3,5-37}$ The literature suggests adult and pediatric VSs differ significantly in tumor characteristics, such as the vascularity and speed of growth of the tumors. Existing knowledge regarding adult VSs should not be applied to pediatric patients. . $8,29,36,37^{2}$

Due to their low incidence, pediatric sporadic VSs are typically discussed in the literature as case reports and small case series, with a paucity of reliable coalesced data, especially as relates to long-term outcomes. In this study, we aimed to analyze 15 cases treated at our institution between 1997 and 2019, providing a new look at long-term outcomes for these tumors, especially as outcomes are associated with rates of recurrence and re-treatment. We also conducted a systematic review of the literature and meta-analysis to better characterize these rare tumors.

\section{Methods \\ Case Series}

With institutional review board approval, we conducted a retrospective chart review of patients who underwent resection by the senior authors (D.E.A. and J.P.L.) between 1997 and 2019 at Loyola University Medical Center. We identified patients who were 21 years of age or younger with unilateral VS. Patients with a diagnosis of NF2 made at any time available in the medical record, whether before or after surgery, were excluded. Presentation, surgical characteristics, clinical outcomes, and re-treatment were reviewed.

\section{Tumor Sizing, Surgical Approach, and Technique}

Preoperative MRI was used to define the dimensions of the tumor, and the largest dimension of the tumor was recorded. Selection of surgical approach was determined in accordance with the patient's preoperative hearing functionality, anatomical factors such as the size and extension of the tumor, and the distance between the superior petrosal sinus and the jugular bulb. Three different surgical techniques were utilized: retrosigmoid, translabyrinthine, and the combined retrosigmoid-translabyrinthine. Generally, patients with large tumors $(>4 \mathrm{~cm})$ underwent the combined approach, while the translabyrinthine approach was favored for small tumors $(<1.5 \mathrm{~cm})$ when hearing preservation was not an option. The retrosigmoid approach was utilized in hearing preservation cases and in patients without significant medial extension. All 15 surgeries were performed by the senior authors (D.E.A. and J.P.L.) as part of a multidisciplinary cranial-based team composed of a fellowship-trained pediatric neurosurgeon, a neurotologist, and neuroanesthesiology and intraoperative electrophysiological monitoring personnel in the same fashion that adult VSs are treated at our tertiary care academic medical center.

\section{Extent of Resection}

Residual tumor was assessed intraoperatively using a custom 1-cm graduated bayoneted micromeasuring instrument. Extent of tumor resection was divided into 3 groups: gross-total resection (GTR), near-total resection (NTR), and subtotal resection (STR). GTR was defined as total removal per the surgeon's operative note and no observable residual on postoperative MRI. NTR was defined by greater than or equal to $95 \%$ tumor removal. STR was defined as less than $95 \%$ tumor removal.

\section{Literature Review}

A literature review was conducted via the PubMed database using the search terms "pediatric" and "vestibular schwannoma" or "acoustic neuroma." The search was also repeated including the search term "sporadic." Studies that exclusively discussed NF2 were excluded. Studies that reported a mix of NF2 and sporadic tumors were excluded if the sporadic VS data could not be separated out from the NF2 patients described. References from reviewed articles were examined for other potential studies for inclusion. Inclusion required raw data relating to the age of the patients and presenting symptoms. Only peer-reviewed, published papers were included; meeting abstracts and presentations were not considered.

Once the articles were selected, a structured data collection form was utilized. Selected articles and data were reviewed by 2 independent reviewers. When available, raw data were extracted from the full text of reference articles for pediatric sporadic VSs relating to sex, average tumor size, presenting symptoms, surgical approach, complications, and recurrence rates. Occasionally, data relating to sporadic tumors were interpreted by process of elimination. When data specific to NF2 patients were provided without the nominal data for sporadic cases, the NF2 data were subtracted from the totals to get a corrected value for the sporadic cases. Categories in the data collection form for presenting symptoms (e.g., hearing loss, tinnitus) and complications (e.g., CSF leaks, infection, mortality) were selected to include symptoms and complications evaluated in the majority of the source articles.

\section{Statistical Analysis}

Data extracted from the source articles were analyzed with data from the present series. Absent raw data were excluded from the final analysis of that specific parameter alone. Given that most articles did not provide a breakdown of tumor sizes or age by patient but merely provided averages, averages were calculated as weighted means from the averages provided in the source articles. Ranges were provided when they were available in all source articles included in the analysis and omitted if there was insufficient information in the source articles to calculate a range. Whenever possible, PRISMA's checklist and flow diagram were used to guide the selection criteria and statistical analysis of the systemic review and meta-analy$\operatorname{sis}^{38,39}$ (Fig. 1).

\section{Results}

\section{Our Institutional Experience}

Patient Population and Tumor Characteristics

Fifteen patients meeting our inclusion criteria were identified, ranging in age from 12 to 21 years and an average age of 16.5 years. Sex was relatively evenly distributed, with slightly more males (53\%) than females. Tumor 


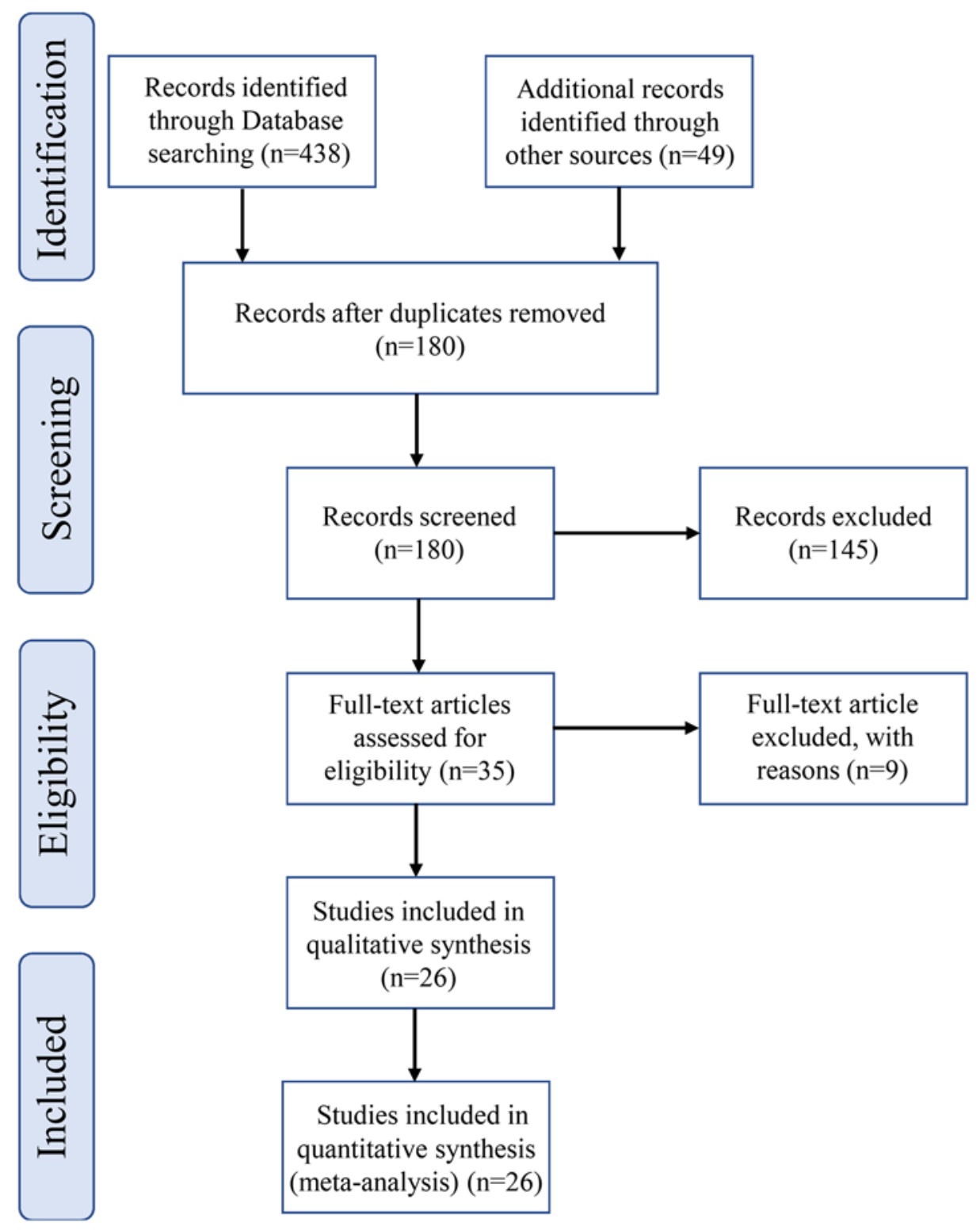

FIG. 1. PRISMA flowchart. Figure is available in color online only.

size ranged from 0.9 to $6.9 \mathrm{~cm}$, with an average size of 3.4 $\mathrm{cm}$. Unlike in the current literature, there were $4(27 \%)$ small tumors $(\leq 1.0 \mathrm{~cm})$. Two $(13 \%)$ tumors, $5.5 \mathrm{~cm}$ and $6.9 \mathrm{~cm}$ in size, were cystic (Table 1).

Common presenting symptoms included sensorineural hearing loss (SNHL) (87\%), headache (40\%), tinnitus $(33 \%)$, dizziness $(33 \%)$, and ataxia $(33 \%)$. Three $(75 \%)$ of the 4 small tumors presented with SNHL and tinnitus. Three tumors were found incidentally $(1 \mathrm{~cm}, 2.5 \mathrm{~cm}$, and $4 \mathrm{~cm}$ ). None of the 15 tumors were found to be hypervascular during resection (Table 2).

\section{Surgical and Radiographic Treatment}

Six (40\%) patients underwent a retrosigmoid approach, 3 (20\%) underwent a translabyrinthine approach, and 6
(40\%) underwent a combined retrosigmoid-translabyrinthine approach. Four (27\%) cases had residual tumor at the time of surgery, ranging in size from a $0.8-\mathrm{cm}$-diameter placode to a $2.8-\mathrm{cm}$ nodule (average $1.5 \mathrm{~cm}$ ). Two of these tumors were thought to have undergone GTR at the time of surgery but were found to have a residual lesion on follow-up MRI. At the time of surgery, 2 tumors were noted to have undergone STR. STR was performed because of dense adherence to the facial nerve in one case and supratentorial tumor extension into a blind spot in the other, which resulted in a $2.8-\mathrm{cm}$ residual. Of these 4 residuals, $3(75 \%)$ had a significant radiographic regrowth within a 4-, 15-, and 40-month follow-up that required a second surgery $(n=2)$ or stereotactic radiosurgery $(S R S ; n=1)$. One of the 2 patients who had undergone an STR of their 
TABLE 1. Present LUMC series: patient characteristics and surgical treatment

\begin{tabular}{|c|c|c|c|c|c|}
\hline $\begin{array}{c}\text { Patient } \\
\text { No. }\end{array}$ & $\begin{array}{c}\text { Age (yrs), } \\
\text { Sex }\end{array}$ & $\begin{array}{c}\text { Tumor } \\
\text { Size }(\mathrm{cm})\end{array}$ & $\begin{array}{l}\text { Surgical } \\
\text { Approach }\end{array}$ & $\begin{array}{l}\text { Extent of } \\
\text { Resection }\end{array}$ & $\begin{array}{l}\text { Regrowth/ } \\
\text { Recurrence }\end{array}$ \\
\hline 1 & $16, F$ & 1 & RS & GTR & No \\
\hline 2 & $17, \mathrm{M}$ & 1 & $\mathrm{TL}$ & GTR & No \\
\hline 3 & $12, \mathrm{~F}$ & 2.5 & TL & GTR & No \\
\hline 4 & $14, \mathrm{M}$ & 5.5 & $\mathrm{RS} / \mathrm{TL}$ & STR & Yes $^{*}$ \\
\hline 5 & $20, M$ & 4.3 & $\mathrm{RS} / \mathrm{TL}$ & STR & Yes \\
\hline 6 & $21, F$ & 1 & RS & GTR & No \\
\hline 7 & $21, \mathrm{M}$ & 1.6 & $\mathrm{RS}$ & GTR & No \\
\hline 8 & $15, \mathrm{M}$ & 4 & RS & GTR & No \\
\hline 9 & $12, \mathrm{~F}$ & 0.9 & $\mathrm{TL}$ & GTR & No \\
\hline 10 & $13, F$ & 6.9 & $\mathrm{RS}$ & NTR & Yes* \\
\hline 11 & $18, F$ & 4.5 & $\mathrm{RS} / \mathrm{TL}$ & NTR & Yes* \\
\hline 12 & $16, F$ & 5.5 & $\mathrm{RS} / \mathrm{TL}$ & GTR & Yes \\
\hline 13 & $20, M$ & 6 & $\mathrm{RS} / \mathrm{TL}$ & GTR & No \\
\hline 14 & $16, \mathrm{M}$ & 4 & $\mathrm{RS} / \mathrm{TL}$ & GTR & No \\
\hline 15 & $17, \mathrm{M}$ & 2.3 & RS & GTR & No \\
\hline
\end{tabular}

LUMC = Loyola University Medical Center; RS = retrosigmoid; TL = translabyrinthine.

${ }^{*}$ Required re-treatment.

initial tumor underwent a second STR 15 months after initial resection and required a third resection 10 months after that due to continued regrowth of the tumor. The patient who underwent SRS 4 months after initial resection also required re-resection 24 months after SRS treatment, due to continued growth of the residual tumor. One patient (patient 12), with GTR of a $5.5-\mathrm{cm}$ tumor, had recurrence measuring approximately $1.0 \mathrm{~cm} 160$ months following resection and has opted for observation. At 262 months following the initial resection, the residual measured approximately $1.2 \mathrm{~cm}$ (Table 1 ).

\section{Facial Nerve Outcomes and Postoperative Complications}

Fourteen (93\%) patients had a good long-term facial nerve outcome with a House-Brackmann (HB) grade I or II following initial resection (see Table 5). Two patients had initial postoperative HB grades III and VI and recovered to grades I and II, respectively. One patient had initial postoperative HB IV, which remained stable until the patient underwent facial reanimation surgery 18 years later. A patient with normal facial function following the first resection underwent 2 subsequent operations for regrowth and worsened to $\mathrm{HB} \mathrm{V}$ following the third surgery.

There was a low incidence of postoperative complications, with only 1 patient (patient 4), who underwent 3 resections experiencing dizziness, tinnitus, and headache. One patient (patient 1) developed a wound infection, which was treated surgically 2 months after initial resection. There were no mortalities in our case series.

\section{Systematic Review and Meta-Analysis}

A total of 35 papers discussing 118 sporadic pediatric VSs were identified and selected for potential inclusion. Of those 35 papers, 2 studies were excluded due to their patients being older than 21 years or not being examined for NF2. Six additional studies that did not include raw data relating to the patient age or only provided the patient age and tumor size with no additional information were also excluded. Finally, 1 study by Walcott et al. that was coauthored by our same senior authors in 2009 and discussed 6 of the 15 patients reported in the current case review was also excluded. ${ }^{35}$ Whenever possible, each individual study was assessed for bias; however, due to the nature of the source-article case reports, many from the 1940s, 1950s, and 1970s, there was rarely sufficient information by which to judge the risk of bias. As a result, no confidence intervals, forest plots, or subgroup analyses were calculated.

A total of 96 patients were spread over 26 articles and our current review with sufficient raw data to be included in our analysis. Sex was evenly split, with 48 males and

TABLE 2. Present LUMC series: presenting symptoms

\begin{tabular}{cccccccccc}
\hline Patient No. & SNHL & Tinnitus & Headache & Dizziness & Elevated ICP & Ataxia & Hypesthesia & Facial Numbness & Facial Palsy \\
\hline 1 & No & No & Yes & No & No & No & No & No & No \\
\hline 2 & Yes & Yes & No & Yes & No & No & No & No & No \\
\hline 3 & Yes & No & No & No & No & No & No & No & No \\
\hline 4 & Yes & Yes & No & No & No & No & No & No & No \\
\hline 5 & Yes & No & Yes & No & Yes & Yes & No & No & No \\
\hline 6 & Yes & Yes & No & Yes & No & Yes & No & No & No \\
\hline 7 & Yes & No & No & Yes & No & No & No & No & Yes \\
\hline 8 & Yes & Yes & Yes & Yes & No & Yes & No & No & No \\
\hline 9 & Yes & Yes & No & No & No & No & No & No & No \\
\hline 10 & Yes & No & Yes & Yes & Yes & Yes & Yes & No & No \\
\hline 11 & Yes & No & No & No & Yes & No & Yes & No & No \\
\hline 12 & Yes & No & Yes & No & Yes & No & No & Yes & No \\
\hline 13 & Yes & No & Yes & No & No & No & No & No & No \\
\hline 14 & No & No & No & No & No & No & No & No & No \\
\hline 15 & Yes & No & No & No & No & Yes & No & No & No \\
\hline
\end{tabular}


TABLE 3. Meta-analysis: patient characteristics

\begin{tabular}{|c|c|c|c|c|c|c|c|c|c|c|}
\hline \multirow[b]{2}{*}{ Authors \& Year } & \multirow{2}{*}{$\begin{array}{c}\text { No. of } \\
\text { Patients }\end{array}$} & \multirow{2}{*}{$\begin{array}{c}\text { Avg Age } \\
\text { (yrs) }\end{array}$} & \multirow{2}{*}{$\begin{array}{c}\text { Avg Tumor } \\
\text { Size }(\mathrm{cm})\end{array}$} & \multicolumn{7}{|c|}{ Presenting Symptom } \\
\hline & & & & SNHL & Ataxia & Facial Palsy & Elevated ICP & Headache & Dizziness & Tinnitus \\
\hline Present LUMC series & 15 & 16.5 & 3.4 & 13 & 5 & 1 & 4 & 6 & 5 & 5 \\
\hline Başar, $2018^{9}$ & 8 & 15 & 4.23 & 8 & 3 & 2 & 3 & 3 & NR & 5 \\
\hline Yin et al., $2017^{37}$ & 10 & 14 & 5.15 & 10 & 9 & 4 & 9 & 9 & NR & 5 \\
\hline Wang et al., $2015^{36}$ & 1 & 15 & 1 & 1 & 0 & 0 & 0 & 0 & 0 & 0 \\
\hline Mazzoni et al., $2007^{28}$ & 10 & 16 & 2.19 & 8 & NR & NR & NR & 1 & 3 & 4 \\
\hline Mirzayan et al., $2007^{29}$ & 20 & 19 & 3.5 & 12 & 2 & 2 & 3 & NR & 3 & 6 \\
\hline Pothula et al., $2001^{31}$ & 3 & 11 & 5.3 & 2 & 1 & 1 & 3 & 2 & 0 & 0 \\
\hline Harada et al., $2000^{17}$ & 1 & 10 & 4.8 & 1 & 1 & 0 & 0 & 0 & 1 & 0 \\
\hline Lang et al., $1998^{24}$ & 3 & 13 & $>3.5$ & 3 & 3 & NR & NR & NR & NR & NR \\
\hline Ishikawa et al., $1997^{19}$ & 3 & 14 & 3 & 3 & 0 & 1 & 0 & 0 & 1 & 1 \\
\hline Sells \& Hurley, $1994^{33}$ & 1 & 15 & 3 & 1 & 0 & 0 & 0 & 0 & 0 & 0 \\
\hline Chen et al., $1992^{11}$ & 1 & 6 & 2 & 1 & 0 & 0 & 0 & 0 & 0 & 0 \\
\hline Allcutt et al., $1991^{7}$ & 3 & 13.7 & 4 & 3 & 1 & 1 & 2 & 3 & 0 & 0 \\
\hline Mattucci et al., $1987^{27}$ & 1 & 10 & 4.5 & 1 & 0 & 0 & 0 & 1 & 0 & 0 \\
\hline Phelps \& Lloyd, $1987^{30}$ & 1 & 9 & NR & 1 & 0 & 0 & 0 & 0 & 0 & 0 \\
\hline Rushworth et al., $1984^{32}$ & 1 & 9 & NR & 1 & 1 & 1 & 1 & 1 & 0 & 0 \\
\hline Vassilouthis \& Richardson, $1979^{34}$ & 1 & 10 & NR & 1 & 1 & 1 & 1 & 1 & 0 & 1 \\
\hline Frank et al., $1978^{14}$ & 1 & 9 & 5 & 1 & 0 & 0 & 0 & 1 & 0 & 0 \\
\hline Gaini et al., $1976^{15}$ & 4 & 14.5 & NR & 1 & 4 & 3 & 4 & 3 & 0 & 0 \\
\hline Laha \& Huestis, $1975^{23}$ & 1 & 10 & NR & 1 & 1 & 1 & 1 & 1 & 0 & 1 \\
\hline Anderson \& Bentinck, $1972^{8}$ & 1 & 13 & NR & 1 & 1 & 0 & 1 & 1 & 0 & 1 \\
\hline Krause \& McCabe, $1971^{21}$ & 1 & 7.5 & 1.7 & 1 & 0 & 1 & 0 & 1 & 0 & 0 \\
\hline Bjorkesten, $1957^{10}$ & 1 & 12 & NR & 1 & 1 & 1 & 0 & 0 & 0 & 0 \\
\hline Craig et al., $1954^{12}$ & 2 & 12.5 & 8 & 2 & 1 & 2 & 2 & 2 & 1 & 2 \\
\hline Mark \& Sweet, $1952^{26}$ & 1 & 8.5 & NR & 1 & 1 & 1 & 0 & 0 & 1 & 0 \\
\hline Hodes et al., $1949^{18}$ & 1 & 14 & NR & 1 & 1 & 1 & 0 & 0 & 0 & 1 \\
\hline
\end{tabular}

$\mathrm{Avg}=$ average; $\mathrm{NR}=$ not reported.

48 females. The overall average age at diagnosis was 12.1 years (range 6-21 years). The average tumor size for the 81 patients with available data was $4.1 \mathrm{~cm}$. Only 9 tumors, 4 from our current review, were described in the literature as being smaller than $1.5 \mathrm{~cm}$ in size (Table 3).

The most commonly described presenting symptoms were hearing loss $(83 \%)$, headache (49\%), ataxia/cerebellar dysfunction (43\%), elevated intracranial pressure (ICP) (41\%), tinnitus (34\%), and dizziness/vertigo (20\%). Notably, there were 24 reported cases of facial palsy, 18 reported cases of trigeminal hypesthesia, and 12 cases of nystagmus (Table 3 ).

One patient was treated with SRS, whereas the remaining 95 patients were treated surgically. Of the 74 cases that described the surgical approach, the retrosigmoid approach was the most common, used in $72 \%$ of cases, followed by translabyrinthine in $16 \%$, combined retrosigmoid-translabyrinthine approach in $8 \%$, middle fossa approach in 1\%, and an alternative approach in $3 \%$ (Table 4).

Of the 90 cases with reported postoperative complications, the most common complications described were decline in facial function (15\%), CSF leak (6\%), hemorrhage (4\%), headache (3\%), and infection (2\%), with 1 documented case each of stroke, seizures, and cerebellar swelling.

TABLE 4. Meta-analysis: surgical approach

\begin{tabular}{|c|c|c|c|c|c|c|}
\hline Authors \& Year & $\begin{array}{c}\text { No. of } \\
\text { Patients }\end{array}$ & $\begin{array}{c}\% \\
\mathrm{RS}\end{array}$ & $\begin{array}{l}\% \\
\mathrm{TL}\end{array}$ & $\begin{array}{c}\% \\
\mathrm{RS} / \mathrm{TL}\end{array}$ & $\begin{array}{c}\% \\
\text { MF }\end{array}$ & $\begin{array}{c}\% \\
\text { Other }\end{array}$ \\
\hline $\begin{array}{l}\text { Present LUMC series, } \\
2019\end{array}$ & 15 & 40 & 20 & 40 & 0 & 0 \\
\hline Başar, $2018^{9}$ & 8 & 100 & 0 & 0 & 0 & 0 \\
\hline Yin et al., $2017^{37}$ & 10 & 100 & 0 & 0 & 0 & 0 \\
\hline Mazzoni et al., $2007^{28}$ & 10 & 50 & 50 & 0 & 0 & 0 \\
\hline Mirzayan et al., $2007^{29}$ & 20 & 100 & 0 & 0 & 0 & 0 \\
\hline Pothula et al., $2001^{31}$ & 3 & 67 & 0 & 0 & 0 & 33 \\
\hline Lang et al., $1998^{24}$ & 3 & 0 & 100 & 0 & 0 & 0 \\
\hline Ishikawa et al., $1997^{19}$ & 3 & 33 & 0 & 0 & 33 & 33 \\
\hline Chen et al., $1992^{11}$ & 1 & 100 & 0 & 0 & 0 & 0 \\
\hline Krause \& McCabe, $1971^{21}$ & 1 & 0 & 100 & 0 & 0 & 0 \\
\hline
\end{tabular}

$\mathrm{MF}=$ middle fossa.

Articles that did not report the surgical approach(es) were excluded. 
TABLE 5. Meta-analysis: HB grades

\begin{tabular}{|c|c|c|c|c|c|c|c|}
\hline \multirow[b]{2}{*}{ Authors \& Year } & \multirow[b]{2}{*}{ No. of Patients* } & \multicolumn{6}{|c|}{ HB Grade, $\%$} \\
\hline & & I & ॥ & III & IV & V & VI \\
\hline Present LUMC series, 2019 & 15 & 73 & 20 & 0 & 7 & 0 & 0 \\
\hline Başar, $2018^{9}$ & 8 & \multicolumn{2}{|c|}{50} & \multicolumn{2}{|c|}{25} & \multicolumn{2}{|c|}{25} \\
\hline Yin et al., $2017^{37}$ & $10(8)$ & 10 & \multicolumn{2}{|c|}{50} & \multicolumn{2}{|c|}{20} & NR \\
\hline Wang et al., $2015^{36}$ & 1 & 100 & 0 & 0 & 0 & 0 & 0 \\
\hline Mazzoni et al., $2007^{28}$ & 10 & 70 & 10 & 10 & 0 & 10 & 0 \\
\hline Mirzayan et al., $2007^{29}$ & 20 & \multicolumn{2}{|c|}{95} & 0 & 0 & \multicolumn{2}{|c|}{5} \\
\hline Pothula et al., $2001^{31}$ & $3(1)$ & 33 & NR & NR & NR & NR & NR \\
\hline Harada et al., $2000^{17}$ & 1 & 100 & 0 & 0 & 0 & 0 & 0 \\
\hline Lang et al., $1998^{24}$ & 3 & 0 & 100 & 0 & 0 & 0 & 0 \\
\hline Ishikawa et al., $1997^{19}$ & $3(2)$ & 67 & NR & NR & NR & NR & NR \\
\hline Sells \& Hurley, $1994^{33}$ & 1 & 100 & 0 & 0 & 0 & 0 & 0 \\
\hline Chen et al., $1992^{11}$ & 1 & 100 & 0 & 0 & 0 & 0 & 0 \\
\hline Allcutt et al., $1991^{7}$ & $3(2)$ & 67 & NR & NR & NR & NR & NR \\
\hline Rushworth et al., $1984^{32}$ & 1 & 0 & 0 & 0 & 0 & 0 & 100 \\
\hline Vassilouthis \& Richardson, $1979^{34}$ & 1 & 0 & 0 & 0 & 0 & 0 & 100 \\
\hline Frank et al., $1978^{14}$ & 1 & 100 & 0 & 0 & 0 & 0 & 0 \\
\hline Laha \& Huestis, $1975^{23}$ & 1 & 100 & 0 & 0 & 0 & 0 & 0 \\
\hline Krause \& McCabe, $1971^{21}$ & 1 & 0 & 0 & 0 & 0 & 0 & 100 \\
\hline Bjorkesten, $1957^{10}$ & 1 & 0 & 0 & 0 & 0 & 0 & 100 \\
\hline Mark \& Sweet, $1952^{26}$ & 1 & 0 & 0 & 0 & 0 & 0 & 100 \\
\hline
\end{tabular}

The mortality rate was 3\%. Five articles reported $6(6 \%)$ hypervascular tumors, 3 of which underwent a 2 -stage surgery due to intraoperative bleeding. Postoperative facial function was reported for 80 cases (Table 5).

Although 16 tumor residuals were noted in the literature, only 12 patients had follow-up beyond the surgery, with an average follow-up of 27 months. Of those 12 patients with residuals, $6(50 \%)$ patients had a regrowth, with 5 re-treatments; 2 (3\%) patients experienced recurrence following a GTR.

\section{Discussion}

The 15 pediatric patients with sporadic VS presented in our case series serve as an update to the 7-patient series published in 2009 by the same surgical team (D.E.A. and J.P.L.). This enabled a more comprehensive study of long-term outcomes, recurrences, and complications with 10 additional years of follow-up. ${ }^{35}$ One of the 7 patients from the 2009 case series was excluded from the current cohort because they went on to be diagnosed with NF2. Thus, of the 16 pediatric patients treated at our institution presenting with unilateral sporadic VS between 1997 and $2019,1(6 \%)$ went on to be diagnosed with NF2. Although none of the 15 patients in the present series have a family history of NF2 or displayed any features suggestive of NF2 during the average follow-up of 60 months, the possibility that some may go on to develop NF2 over time must be acknowledged. Additionally, this risk of NF2 is equally true for the patients included in the meta-analysis and should be taken into consideration in the treatment decision-making and follow-up of all apparently sporadic VSs. Although bilateral VSs are the most frequent presentation of NF2, a retrospective review showed that as many as $10 \%-25 \%$ of VSs in NF2 are initially unilateral at presentation. ${ }^{13,31}$ Evans et al. showed this risk to be greatest for patients younger than 30 years. ${ }^{13,40}$ The same study showed as many as $6 \%$ of individuals with an apparently isolated VS to be mosaic for NF2 and go on to develop other NF2 features. ${ }^{40}$

Holman et al. found SNHL to be the most common presenting symptom of pediatric VS, noting that it occurred more frequently in the sporadic $(69 \%)$ than NF2 (25\%) cases, ${ }^{6}$ which is corroborated by our case series $(87 \%)$ and meta-analysis (80\%). This aligns with hearing loss as a presenting symptom in sporadic adult VS. ${ }^{2}$ Our series also mirrored other presenting symptoms of adult VS, including headaches (40\%) and tinnitus (33\%) as the second and third most common presenting symptoms. This was not true in our meta-analysis, which showed ataxia and cerebellar dysfunction (43\%) and signs of elevated ICP (41\%) to be the next most frequent presenting symptoms after hearing loss and headache. This discrepancy may be due to the higher than typical small tumors in our series of 15 patients compared with the meta-analysis. The average presenting tumor size of $4.1 \mathrm{~cm}$ from our meta-analysis is much larger than that in adults, which, in a study of 6225 adult patients, was found to be $1.6 \mathrm{~cm} .^{2}$ Thus, pediatric 
VSs, with their average increased size at presentation, are more likely to cause symptoms due to mass effect and increased ICP than their adult counterparts.

Notably, our meta-analysis showed an unexpectedly high number of patients presenting with facial palsy ( $\mathrm{n}=$ 24 ) and trigeminal hypesthesia $(n=18)$, although this was not seen in our institutional series. While the trigeminal effects are likely explained by the larger size on average of pediatric VS compared with adult VS, as this symptom is known to occur with large compressive VSs, the facial palsy is more puzzling as it is more commonly associated with facial schwannomas. ${ }^{41,42}$ Although this discrepancy may be due to inaccurate reporting, many of these patients with facial palsy were confirmed during surgery and on histology to have VS. Additionally, Evans et al. found a high number of pediatric NF2 patients with facial palsy, although they attributed it in part to non-tumor-related causes. $^{43}$

Beyond the differences in presenting symptoms between pediatric and adult VS, differences in tumor characteristics have also been suggested. Pediatric VSs have been thought to be more aggressive and vascular, although no hypervascular tumors were noted in our series. Unfortunately, vascularity was not reported consistently in the literature, making it difficult to evaluate in our meta-analysis; however, 6 cases of hypervascular VS were described.7,31,32,37 Yamakami et al. noted that hypervascular VS presented at a younger age than nonhypervascular tumors, and thus this risk should be considered when approaching treatment for these rare tumors. ${ }^{44}$ Interestingly, several of the articles mentioned approaching the hypervascular tumors through a staged approach, where on second surgery they found the tumor to be devascularized and easier to remove, although this has not been necessary in our experiences.

We found pediatric VS to be more aggressive than adult VS in terms of residual regrowth and recurrence, with 5 (38\%) of the 13 patients who had at least a 1-year follow-up experiencing regrowth. There are inconsistencies in the literature on the regrowth rates of VS in adults, with reports of regrowth rates mostly around $20 \%$, but ranging from $13.6 \%$ to $50 \%{ }^{45-51}$ In our unpublished sporadic VS series of 862 patients treated by the same senior authors (D.E.A. and J.P.L.), 113 (13\%) had a residual tumor following surgery and, of those, $18(16 \%)$ had regrowth resulting in retreatment. Although the pediatric data are a small sample size, the more than 2-fold difference in recurrence and regrowth rates between our pediatric and adult population suggest that a more aggressive approach to treatment may prove to be warranted in the pediatric population. This is also suggested by the speed of regrowth, with 2 of the 5 patients with regrowth/recurrence occurring rapidly, at 4 and 15 months. However, defining the behavior of tumors in the pediatric population from a small cohort of patients must be tempered.

The 1-cm graduated bayoneted micromeasuring instrument used by the senior authors to intraoperatively assess residual tumor is a helpful adjunct to postoperative imaging. Unfortunately, there are inherent inaccuracies in measuring residuals intraoperatively, as depth is difficult to take into account. Postoperative MRI is a standard tool for residual assessment; however, there can be difficulty dif-

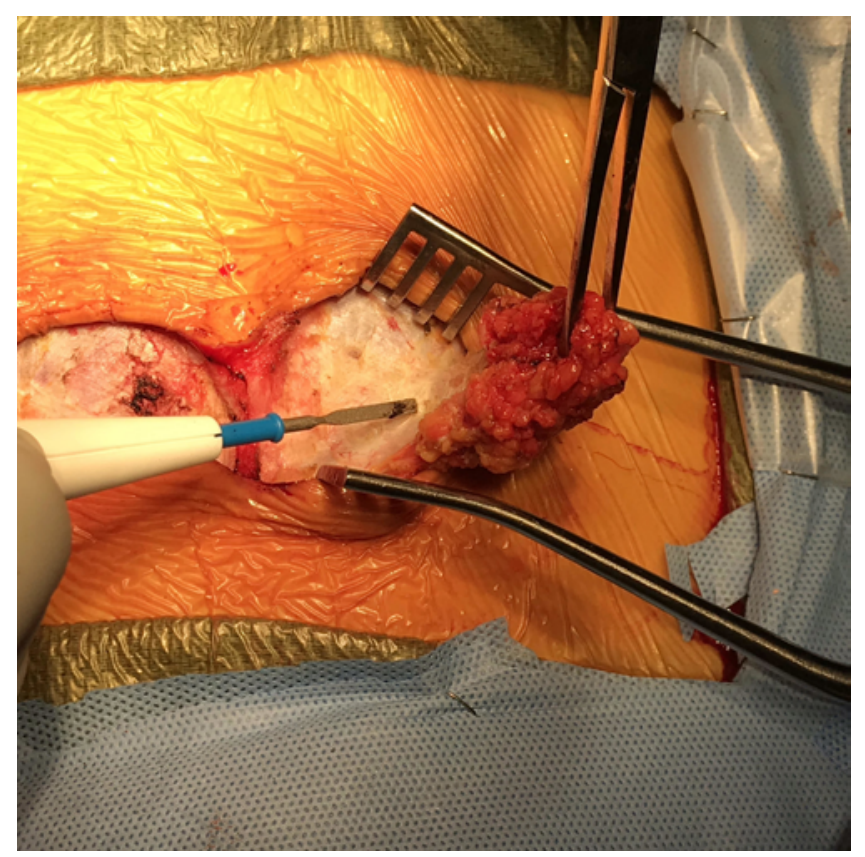

FIG. 2. Image of the bilateral paramedian fat harvest surgery.

ferentiating residual tumor from contrast-enhancing postoperative changes. It has been the practice of the senior authors to collate the postoperative imaging findings with intraoperative measurements to determine the presence and size of residual tumor. Despite this, it is possible that the residual sizes are misestimated, and this may have an impact on their extent of resection classification, and the subsequent expected risk of regrowth.

With surgical approach in mind, it is important to note that data show that facial nerve function is a major predictor of postoperative quality of life..$^{48,52-55}$ This holds especially true in the pediatric population, who have a much longer event horizon than the typical surgical candidate. While some studies of adult patients support STR or NTR in favor of preserved facial nerve function due to the low recurrence and low/slow regrowth rate of adult VS, this may not be true for their pediatric counterparts. ${ }^{53-55}$ Our data suggest that pediatric tumors may be more aggressive, with higher regrowth rates than adults, and this increased risk must be balanced with the major impact on quality of life that disrupted facial function can have on the pediatric patient. Although we continue to favor facial function preservation over complete resection in the pediatric population, it is recommended that this population may require much closer follow-up than their adult counterparts, and the physicians must discuss the risk of recurrence/regrowth with patients and their families.

Of note, our senior authors have noted difficulty obtaining sufficient abdominal fat graft in pediatric patients. This is likely due to the different fat distributions in these young patients and should be taken into account. We have found success in using bilateral paramedian fat harvest (Fig. 2).

Although radiosurgery is another treatment option, only 1 case has been reported for a pediatric patient. ${ }^{36}$ This preference for surgical treatment is likely due to concerns of radiation exposure in these young patients, some 
of whom are still growing, the long event horizon for secondary neoplasm growth, and increasing evidence of longterm hearing decline post-SRS. ${ }^{52}$

Given the high recurrence rate demonstrated in our analysis, there may be a role for future studies to address the use of adjuvant therapy in pediatric patients; however, there would still be concerns of radiation exposure.

While loss of facial function is the most common complication of pediatric VS resection aside from anticipated hearing loss, CSF leaks (6\%), hemorrhage (4\%), headache $(3 \%)$, and infection $(2 \%)$ also occur. Three fatalities were reported of the 96-patient meta-analysis cohort, but of note, two of these occurred during surgeries in 1976.

Study limitations include a small sample size and heterogeneous follow-up, and limitations inherent to a retrospective series and meta-analysis. As previously noted, limitations to tumor residual measurements exist both intraoperatively and on postoperative imaging. Additionally, as a single-center study, selection bias may be inherent to referral patterns for patients who are favored for surgery. Given the 22-year duration of study for our cohort of pediatric patients, it is reasonable to expect some element of a learning curve impacting the care and outcome for these patients. The small number of pediatric cases, low complication rate, and the experience brought from our center from being a high-volume center for adult VS are other confounding factors to the generalizability of our series. We have found that a consistent and multidisciplinary team, including those accustomed to pediatric patients and posterior fossa neurosurgical pathologies, as well as developing a high surgical volume, can contribute to optimal outcomes.

\section{Conclusions}

Sporadic pediatric VSs are rare lesions that appear to be more aggressive than their adult counterparts, with high regrowth and recurrence rates, suggesting that more frequent MRI surveillance may be in order for this population. The incidence of many presenting symptoms parallels that of adult patients with sporadic VS, although symptoms of mass effect are more common, as are facial palsy, although this is controversial. These tumors tend to be larger at diagnosis than in adults, although small tumors in children are discovered and are successfully treated surgically.

\section{References}

1. DeLong M, Kirkpatrick J, Cummings T, Adamson DC. Vestibular schwannomas: lessons for the neurosurgeon. Part II: Molecular biology and histology. Contemp Neurosurg. 2011;33:1-3.

2. Babu R, Sharma R, Bagley JH, et al. Vestibular schwannomas in the modern era: epidemiology, treatment trends, and disparities in management. J Neurosurg. 2013;119(1):121-130.

3. Stangerup SE, Tos M, Thomsen J, Caye-Thomasen P. True incidence of vestibular schwannoma? Neurosurgery. 2010;67(5):1335-1340.

4. Tos M, Charabi S, Thomsen J. Incidence of vestibular schwannomas. Laryngoscope. 1999;109(5):736-740.

5. Bonne N, Aboukais R, Baroncini M, et al. Pediatric neurofibromatosis type 2: clinical and molecular presentation, management of vestibular schwannomas, and hearing rehabilitation. Childs Nerv Syst. 2016;32(12):2403-2413.
6. Holman MA, Schmitt WR, Carlson ML, et al. Pediatric cerebellopontine angle and internal auditory canal tumors: clinical article. J Neurosurg Pediatr. 2013;12(4):317-324.

7. Allcutt DA, Hoffman HJ, Isla A, et al. Acoustic schwannomas in children. Neurosurgery. 1991;29(1):14-18.

8. Anderson MS, Bentinck BR. Intracranial schwannoma in a child. Cancer. 1972;29(1):231-234.

9. Başar İ: Pediatric vestibular schwannomas: evaluation of clinical features, treatment strategies and long-term results of 10 cases. $\operatorname{Tr}$-ENT. 2018;28(3):116-125.

10. Bjorkesten GA. Unilateral acoustic tumours in children. Acta Psychiatr Neurol Scand. 1957;32(1):1-5.

11. Chen TC, Maceri DR, Giannotta SL, et al. Unilateral acoustic neuromas in childhood without evidence of neurofibromatosis: case report and review of the literature. Am J Otol. 1992;13(4):318-322.

12. Craig WM, Dodge HW Jr, Ross PJ. Acoustic neuromas in children: report of 2 cases. J Neurosurg. 1954;11(5):505-508.

13. Evans DG, Lye R, Neary W, et al. Probability of bilateral disease in people presenting with a unilateral vestibular schwannoma. J Neurol Neurosurg Psychiatry. 1999;66(6):764-767.

14. Frank T, May M, Janetta PJ. Acoustic neurinoma in a child: a case study. J Speech Hear Disord. 1978;43(4):506-512.

15. Gaini SM, Giovanelli M, Motti ED, et al. Acoustic neurinomas in infancy. Report on four cases. Mod Probl Paediatr. 1976;18:90-93.

16. Grinblat G, Prasad SC, Fulcheri A, et al. Lateral skull base surgery in a pediatric population: a 25 -year experience in a referral skull base center. Int J Pediatr Otorhinolaryngol. 2017;94:70-75.

17. Harada K, Nishizaki T, Adachi N, et al. Pediatric acoustic schwannoma showing rapid regrowth with high proliferative activity. Childs Nerv Syst. 2000;16(3):134-137.

18. Hodes PJ, Pendergrass EP, Young BR. Eighth nerve tumors; their roentgen manifestations. Radiology. 1949;53(5):633$665,707-710$.

19. Ishikawa $\mathrm{K}$, Yasui N, Monoh $\mathrm{K}$, et al. Unilateral acoustic neuroma in childhood. Auris Nasus Larynx. 1997;24(1):99104.

20. Jackson CG, Pappas DG Jr, Manolidis S, et al. Pediatric neurotologic skull base surgery. Laryngoscope. 1996;106(10):1205-1209.

21. Krause CJ, McCabe BF. Acoustic neuroma in a 7-year-old girl. Report of a case. Arch Otolaryngol. 1971;94(4):359-363.

22. Kusunose M, Nishijima M, Oka N, et al. Acoustic neurinoma in a child. Article in Japanese. No Shinkei Geka. 1990;18(3):301-306.

23. Laha RK, Huestis WS. Unilateral acoustic neuroma and cerebellopontine angle lesions in children. Surg Neurol. 1975;4(4):371-374.

24. Lang DA, Neil-Dwyer G, Evans BT, Honeybul S. Craniofacial access in children. Acta Neurochir (Wien). 1998;140(1):33-40.

25. MacNally SP, Rutherford SA, King AT, et al. Outcome from surgery for vestibular schwannomas in children. Br J Neurosurg. 2009;23(3):226-231.

26. Mark VH, Sweet WH. An unusual case of unilateral eighth nerve tumor. J Neurosurg. 1952;9(4):395-397.

27. Mattucci KF, Glass WM, Setzen M, Levin W. Childhood acoustic neuroma. $N$ Y State J Med. 1987;87(12):665-666.

28. Mazzoni A, Dubey SP, Poletti AM, Colombo G. Sporadic acoustic neuroma in pediatric patients. Int J Pediatr Otorhinolaryngol. 2007;71(10):1569-1572.

29. Mirzayan MJ, Gerganov VM, Lüdemann W, et al. Management of vestibular schwannomas in young patients-comparison of clinical features and outcome with adult patients. Childs Nerv Syst. 2007;23(8):891-895.

30. Phelps PD, Lloyd GA. Which small acoustic neuromas need surgery? The influence of magnetic resonance and air CT 
meatograms. Clin Otolaryngol Allied Sci. 1987;12(3):191196.

31. Pothula VB, Lesser T, Mallucci C, et al. Vestibular schwannomas in children. Otol Neurotol. 2001;22(6):903-907.

32. Rushworth RG, Sorby WA, Smith SF. Acoustic neuroma in a child treated with the aid of preoperative arterial embolization. Case report. J Neurosurg. 1984;61(2):396-398.

33. Sells JP, Hurley RM. Acoustic neuroma in an adolescent without neurofibromatosis: case study. J Am Acad Audiol. 1994;5(5):349-354.

34. Vassilouthis J, Richardson AE. Acoustic neurinoma in a child. Surg Neurol. 1979;12(1):37-39.

35. Walcott BP, Sivarajan G, Bashinskaya B, et al. Sporadic unilateral vestibular schwannoma in the pediatric population. Clinical article. J Neurosurg Pediatr. 2009;4(2):125-129.

36. Wang J, Xu Y, Lei T, Zeng L. Treatment decision-making for sporadic small vestibular schwannoma in a pediatric patient: a case report and literature review. Oncol Lett. 2015;9(5):2371-2373.

37. Yin L, Ma Z, Li C, Luo S. Unilateral vestibular schwannomas in childhood without evidence of neurofibromatosis: experience of 10 patients at a single institute. Turk Neurosurg. 2017;27(3):333-338.

38. Moher D, Liberati A, Tetzlaff J, Altman DG. Preferred reporting items for systematic reviews and meta-analyses: the PRISMA statement. Ann Intern Med. 2009;151(4):264-269, W64.

39. Murad MH, Montori VM, Ioannidis JP, et al. How to read a systematic review and meta-analysis and apply the results to patient care: users' guides to the medical literature. JAMA. 2014;312(2):171-179.

40. Evans DG, Ramsden RT, Gokhale C, et al. Should NF2 mutation screening be undertaken in patients with an apparently isolated vestibular schwannoma? Clin Genet. 2007;71(4):354358.

41. Karkas A, Lamblin E, Meyer M, et al. Trigeminal nerve deficit in large and compressive acoustic neuromas and its correlation with MRI findings. Otolaryngol Head Neck Surg. 2014;151(4):675-680.

42. McMonagle B, Al-Sanosi A, Croxson G, Fagan P. Facial schwannoma: results of a large case series and review. J Laryngol Otol. 2008;122(11):1139-1150.

43. Evans DG, Birch JM, Ramsden RT. Paediatric presentation of type 2 neurofibromatosis. Arch Dis Child. 1999;81(6):496499.

44. Yamakami I, Kobayashi E, Iwadate Y, et al. Hypervascular vestibular schwannomas. Surg Neurol. 2002;57(2):105-112.

45. Chen Z, Prasad SC, Di Lella F, et al. The behavior of residual tumors and facial nerve outcomes after incomplete excision of vestibular schwannomas. J Neurosurg. 2014;120(6):12781287.

46. Jacob JT, Carlson ML, Driscoll CL, Link MJ. Volumetric analysis of tumor control following subtotal and neartotal resection of vestibular schwannoma. Laryngoscope. 2016;126(8):1877-1882.

47. Kasbekar AV, Adan GH, Beacall A, et al. Growth patterns of residual tumor in preoperatively growing vestibular schwannomas. J Neurol Surg B Skull Base. 2018;79(4):319-324.

48. Kemink JL, Langman AW, Niparko JK, Graham MD. Operative management of acoustic neuromas: the priority of neurologic function over complete resection. Otolaryngol Head Neck Surg. 1991;104(1):96-99.
49. Schwartz MS, Kari E, Strickland BM, et al. Evaluation of the increased use of partial resection of large vestibular schwanommas: facial nerve outcomes and recurrence/regrowth rates. Otol Neurotol. 2013;34(8):1456-1464.

50. Seol HJ, Kim CH, Park CK, et al. Optimal extent of resection in vestibular schwannoma surgery: relationship to recurrence and facial nerve preservation. Neurol Med Chir (Tokyo). 2006;46(4):176-181.

51. Wong RH, Copeland WR, Jacob JT, et al. Anterior extension of tumor is as important as tumor size to facial nerve outcome and extent of resection for vestibular schwannomas. $J$ Neurol Surg B Skull Base. 2017;78(6):473-480.

52. Carlson ML, Jacob JT, Pollock BE, et al. Long-term hearing outcomes following stereotactic radiosurgery for vestibular schwannoma: patterns of hearing loss and variables influencing audiometric decline. J Neurosurg. 2013;118(3):579-587.

53. Kennedy JD, Haines SJ. Review of skull base surgery approaches: with special reference to pediatric patients. $J$ Neurooncol. 1994;20(3):291-312.

54. Myrseth E, Møller P, Pedersen PH, et al. Vestibular schwannomas: clinical results and quality of life after microsurgery or gamma knife radiosurgery. Neurosurgery. 2005;56(5):927935 .

55. Parving A, Tos M, Thomsen J, et al. Some aspects of life quality after surgery for acoustic neuroma. Arch Otolaryngol Head Neck Surg. 1992;118(10):1061-1064.

\section{Disclosures}

The authors report no conflict of interest concerning the materials or methods used in this study or the findings specified in this paper.

\section{Author Contributions}

Conception and design: Anderson, Malina, Heiferman. Acquisition of data: Malina, Riedy, Szujewski, Rezaii. Analysis and interpretation of data: Malina. Drafting the article: Malina, Riedy. Critically revising the article: Anderson, Malina, Heiferman, Riedy, Leonetti. Reviewed submitted version of manuscript: all authors. Approved the final version of the manuscript on behalf of all authors: Anderson. Study supervision: Anderson, Heiferman, Leonetti.

\section{Supplemental Information}

\section{Previous Presentations}

Portions of this work were presented orally at the North American Skull Base Society 29th Annual Meeting, Orlando, Florida, February 15-17, 2019.

\section{Correspondence}

Douglas E. Anderson: Loyola University Stritch School of Medicine, Maywood, IL. dander1@lumc.edu. 